\title{
René Pommier, Être girardien ou ne pas être. Shakespeare expliqué par René Girard
}

\section{Massimiliano Catoni}

\section{(2) OpenEdition}

1 Journals

\section{Edizione digitale}

URL: http://journals.openedition.org/studifrancesi/2291

DOI: 10.4000/studifrancesi.2291

ISSN: 2421-5856

\section{Editore}

Rosenberg \& Sellier

\section{Edizione cartacea}

Data di pubblicazione: 1 aprile 2014

Paginazione: 188-189

ISSN: 0039-2944

\section{Notizia bibliografica digitale}

Massimiliano Catoni, «René Pommier, Être girardien ou ne pas être. Shakespeare expliqué par René Girard », Studi Francesi [Online], 172 (LVIII | I) | 2014, online dal 01 avril 2014, consultato il 18 septembre 2020. URL : http://journals.openedition.org/studifrancesi/2291 ; DOI : https://doi.org/10.4000/ studifrancesi.2291

Questo documento è stato generato automaticamente il 18 settembre 2020.

\section{(c)}

Studi Francesi è distribuita con Licenza Creative Commons Attribuzione - Non commerciale - Non opere derivate 4.0 Internazionale. 


\title{
René Pommier, Être girardien ou ne pas être. Shakespeare expliqué par René Girard
}

\author{
Massimiliano Catoni
}

\section{NOTIZIA}

RENÉ POMMIER, Être girardien ou ne pas être. Shakespeare expliqué par René Girard, Paris, Kimé, 2013, pp. 155.

1 Sbaglierebbe chi pensasse che l'oggetto polemico di questo virulento pamphlet sia esclusivamente René Girard e la sua teoria del desiderio mimetico. Pommier, che pure impiega oltre centocinquanta pagine per demolire - con asfittica spietatezza - il pensiero girardiano, e la sua conseguente applicazione all'opera di Shakespeare («le jour viendra, et cela ne tardera guère sans doute - scrive Pommier -, où tout le monde se rendra compte que celui que l'on prenait pour le plus grand penseur de notre temps en était le plus grand bouffon», p. 148), Pommier, dicevamo, palesa ambizioni decisamente più vaste. Ed è lui stesso a rivelarcele, nelle ultime battute del libro, proprio nel momento in cui si appresta a prendere congedo dal lettore: «on se souviendra alors que, dans le dernier demi-siècle, si René Girard s'est élevé plus haut qu'aucun de ses contemporains sur les trois cimes de la sottise, de la prétention et de la notoriété, bien d'autres crétins gratinés comme Roland Barthes, bien d'autres monstrueux imbéciles comme Lucien Goldmann ont bénéficié d'une immense audience, sans parler de Jacques Lacan» (p. 149). La citazione è lunga, ma necessaria. Soltanto lasciando la parola a Pommier, infatti, possiamo rendere conto del livore messo in campo in questo pamphlet. Livore che, come abbiamo potuto vedere, investe i maggiori rappresentanti della nouvelle critique. Pommier liquida in poche battute un'intera generazione di critici e scrittori. Elegge a proprio uso e consumo i membri di tutta un'accademia dei sopravvalutati. Non mancando, va da sé, di porre al centro della scena - shakespearianamente, potremmo dire - il suo oggetto polemico par excellence: e cioè 
Girard. Si direbbe che Girard, a giudizio di Pommier, raccolga su di sé i mali di tutta un'epoca: «on se souviendra aussi que, pendant cette période, le monde universitaire aura été sous la coupe des tenants du structuralisme et de la sémiotique qui auront réussi à imposer à la grande majorité des étudiants la lecture de leurs livres aussi ineptes qu'indigestes» (p. 149).

2 In conclusione non possiamo che citare ancora una volta Pommier: «quand j'ai écrit mon livre René Girard, un allumé qui se prend pour un phare, je n'avais pas lu son livre sur Shakespeare [...] une fois mon livre terminé, je me suis mis en quête d'une nouvelle tête de Turc et je suis vite arrivé à la conclusion que j'aurais bien du mal à en retrouver une qui puisse rivaliser avec René Girard» (p. 1). È attraverso le lenti del disprezzo che Pommier guarda a Girard e al suo lavoro teorico. Muovendo da questo punto di vista, qualsiasi altra argomentazione di natura critica diventa beffardamente superflua. 